\title{
DamaGIS: a multisource geodatabase for collection of flood-related damage data
}

\author{
Clotilde Saint-Martin ${ }^{1}$, Pierre Javelle ${ }^{1}$, and Freddy Vinet ${ }^{2}$ \\ ${ }^{1}$ Institut de Recherche pour l'Ingénierie de l'Agriculture et de l'Environnement, IRSTEA, \\ Unité de recherche RECOVER, Aix-en-Provence, France \\ ${ }^{2}$ Université Paul Valery Montpellier III, Montpellier, France \\ Correspondence: Clotilde Saint-Martin (clotilde.saint-martin@irstea.fr) \\ Received: 27 February 2018 - Discussion started: 2 March 2018 \\ Revised: 4 May 2018 - Accepted: 12 May 2018 - Published: 7 June 2018
}

\begin{abstract}
Every year in France, recurring flood events result in several million euros of damage, and reducing the heavy consequences of floods has become a high priority. However, actions to reduce the impact of floods are often hindered by the lack of damage data on past flood events. The present paper introduces a new database for collection and assessment of flood-related damage. The DamaGIS database offers an innovative bottom-up approach to gather and identify damage data from multiple sources, including new media. The study area has been defined as the south of France considering the high frequency of floods over the past years. This paper presents the structure and contents of the database. It also presents operating instructions in order to keep collecting damage data within the database. This paper also describes an easily reproducible method to assess the severity of flood damage regardless of the location or date of occurrence. A first analysis of the damage contents is also provided in order to assess data quality and the relevance of the database. According to this analysis, despite its lack of comprehensiveness, the DamaGIS database presents many advantages. Indeed, DamaGIS provides a high accuracy of data as well as simplicity of use. It also has the additional benefit of being accessible in multiple formats and is open access. The DamaGIS database is available at https://doi.org/10.5281/zenodo.1241089.
\end{abstract}

\section{Introduction}

Between 1995 and 2015, floods have affected more than 2.3 billion people and caused about USD 662 billion in damage around the world. By comparison, landslides and wildfires have affected 8 million people and caused USD 100 billion in damage, whereas all geophysical hazards combined have caused USD 787 billion in damage in the same period of time (Wallemacq et al., 2015). Although the current situation is already alarming, different studies have estimated that the socioeconomic impact of river floods will more than triple by the end of the century due to continued changes in land use (Alfieri et al., 2015; Pigeon, 2002; Munich RE, 2017). Moreover for the future, it is planned that climate change will also contribute significantly to the increase of human exposure to floods (Pachauri et al., 2014).

To date in France, the insurance trade associations have estimated the total cost of flood-related damage at EUR 1-
1.4 billion a year (Bourguignon, 2014). For example, floods in the Alpes-Maritimes area in October 2015 resulted in 20 fatalities and a total amount of estimated damage greater than EUR 600 million (Saint-Martin et al., 2016; CCR, 2017). More recently, from May to June 2016, large parts of the Parisian basin were also flooded. More than 2000 municipalities were affected by this event for a total cost of damage to insured goods higher than EUR 1.4 billion (Van Oldenborgh et al., 2016; Ramos et al., 2017; CCR, 2016).

In 2015, the Sendai Framework for Disaster Risk Reduction defined four new priorities for action to reduce the impact of disasters around the world. Because of this, the need to "Systematically evaluate, record, share and publicly account for disaster losses" (UNISDR, 2015) was acknowledged as a major priority. It has been shown that collection of loss data would help to increase knowledge on disasters, in- 
cluding floods, and thereby reduce their consequences (Molinari et al., 2017).

\subsection{Damage data collection}

Although the word "damage" is usually defined as physical harm caused to an object, the concept of "flood damage" may refer to a wide range of items. There is a common understanding that flood damage can be described as direct or indirect as well as tangible or intangible (Parker, 2000). We may refer to the notion of direct damage if caused by contact with flood water. On the other hand, tangible damage results if damage can be measured in monetary value and thus objectively quantified (Parker et al., 1987; Smith and Ward, 1998). This paper only focuses on direct and tangible damage data to enable the assessment of damage severity.

The need for a comprehensive and inclusive flood damage database has been underlined by many authors over the years (Gerl et al., 2016; Mileti, 1999; NRC, 1999; Dilley, 2005; Bubeck et al., 2011; Elmer, 2012). The most prominent disaster-related damage databases used today are EMDAT and NatCat (Kron et al., 2012). The emergency events database (EM-DAT) is a free and worldwide database on disaster-related damage using multiple sources (Guha-Sapir et al., 2015; Hoyois and Guha-Sapir, 2003). It contains information on fatalities and costs resulting from more than 20000 disasters which have occurred since 1900. However, EM-DAT is only available at a country level and does not offer information on the type of damage. The Munich RE NatCatService private database also provides information on the natural disasters that have taken place since 1980 around the world. It also provides information on damage costs and fatalities per event at a regional scale, which is more precise than the EM-DAT database (Guha-Sapir and Below, 2002). However, information on the type of damage is still lacking. At the European scale, the HyMeX project has led to the creation of a database recording the societal impact of Mediterranean floods (Llasat et al., 2013). This database has gathered 385 flood events which occurred between 1981 and 2010. This HyMeX database is more accurate and comprehensive than EM-DAT and NatCat databases. But unfortunately it does not provide details about damage due to flood events.

It is fair to say that the United States is years ahead of the rest of the world with regard to disaster-related damage data collection (Tschoegl et al., 2006). For instance, the American National Oceanic and Atmospheric Administration (NOAA) provides a database for flood fatalities and costs caused by weather events since 1903 at a county level, called the Storm Events Database (Downton et al., 2005; National Climatic Data Center, 2015). SHELDUS is another county-level hazard database for the United States (Hazards and Vulnerability Research Institute, 2013). Unlike NOAA's Storm Events Database, which is foremost interested in weather events independent of loss, SHELDUS focuses on loss data. Between
2008 and 2010, an experiment was also conducted by one of NOAA's laboratories to collect specific data on flash floods called the Severe Hazards Analysis and Verification Experiment (SHAVE; Gourley et al., 2013; Calianno et al., 2013; Ortega et al., 2009).

In Europe, several countries have implemented their own databases on flood damage at the national scale. Germany has the HOWAS21 database (Kreibich et al., 2017), Switzerland the Swiss Flood and Landslide Damage Database (Kron et al., 2012) and Italy the FloodCat database (Molinari et al., 2013). Italy also has developed several projects to enhance the collection of flood damage at the national scale. Among these projects, the AVI (Italian vulnerable area or Aree Vulnerate Italiane) project may be mentioned. The AVI project aimed to create a bibliographical and archive inventory of landslides and floods in Italy based on newspaper screening from 1918 to 1990 (Guzzetti et al., 1994). More recently, the LAND-deFeND (LANDslides and Floods National Database) project has developed a new database structure to store and organize information on landslide and flood events (Napolitano et al., 2018). Both of these projects are very similar initiatives to the work presented in this paper.

In France today, neither an easily accessible nor a complete database on flood-related damage is available at the local scale, that is, at the scale of the municipality. However, an initiative was launched to this effect in 1976 by the French Ministry of Environment, although it did not yield a concrete outcome, as suggested in Molinari et al. (2017).

The French GASPAR database is available at the municipal scale. However, it only contains information on whether or not a municipality has been damaged by a flood and provides no information on damage type or severity. Although insurance companies have been collecting accurate data on flood damage, they only disseminate synthetic data at the department level (through ONRN http://www.onrn.fr/site/, last access: 2 February 2018) or for major events only (through the web site https://erisk.ccr.fr/faces/erisk-accueil.jsp, last access: 2 February 2018). The respect of privacy rights and/or commercial confidentiality makes it difficult to openly communicate information such as damage to private housing. However, even insurance companies do not have access to complete flood damage data. Their data only concern private households and business premises, excluding all information on public infrastructures.

Emergency services also have time-stamped and localized records of their operations during flood events such as rescue services or emergency pumping. However, there are no established standards on how to collect and organize those data at the national scale. This might make them difficult to aggregate but also to use and analyse from one location to another. Moreover, this heterogeneity as well as the confidentiality of these data add to the complexity of acquiring them.

This review of the existing databases on flood-related damage at different scales has made it possible to identify the shortcomings and the requirements that need to be addressed 
in order to implement a new database. This paper presents a new database, called the DamaGIS database, which compiles and structures flood-related damage in the south of France. It is a new approach which aims to provide fine-scale damage data and a preliminary assessment of its severity.

\subsection{Structure of the paper}

Although it is not fully comprehensive, DamaGIS provides a detailed database for flood-related damage combined with an assessment of damage severity. This database has only been implemented in the south of France for now, but this paper initiates a new approach to characterize, organize and share flood damage data at a fine spatial scale. This paper contains the necessary information to understand, use and continue completing the DamaGIS database.

First in Sect. 2, the characteristics of the DamaGIS database are introduced along with its content and organization. Section 3 presents and explains the damage rating method used within the database. In Sect. 4, an analysis of the damage contents is provided. Section 5 presents the benefits, limitations and perspectives of the DamaGIS database.

\section{The DamaGIS database}

\subsection{Sources of information}

DamaGIS is a community-based and multisource database for object-specific flood damage caused by river floods. Since 2011, direct and tangible damage caused by flash floods in the south of France have been systematically collected in the DamaGIS database. To this aim, numerous sources of information have been used for comprehensiveness purposes:

- corporate websites,

- personal blogs,

- local authorities,

- public administration,

- on-site observations,

- social network media (Facebook, Twitter) and videosharing websites (Youtube, Dailymotion), and

- online media.

To ensure data reliability, a direct web link to the sources of information is added to the database for each damage occurrence. For now, DamaGIS data have been manually entered by a small group of people, a very time-consuming process. This bias will be corrected by means of multiple contributors. The objective for the database is to evolve it towards a participatory functioning. However, data may also be directly bought from social media companies using keywords and an

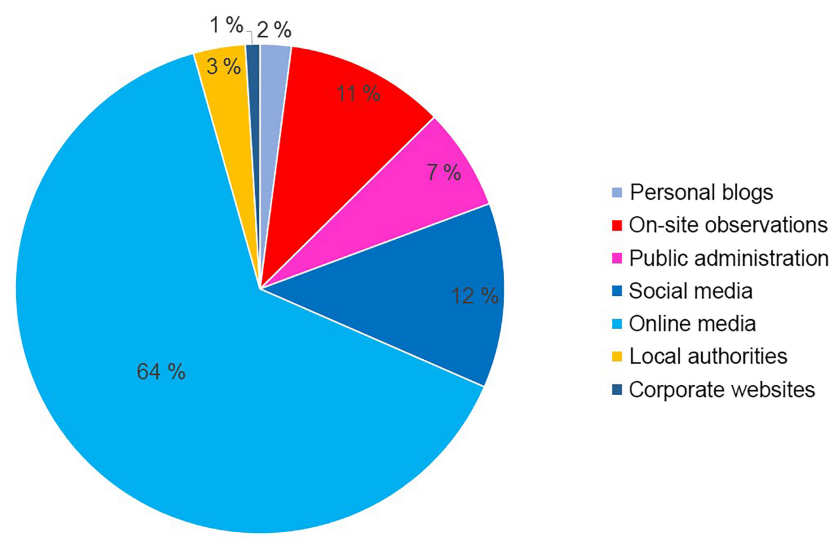

Figure 1. Distribution of data sources in the DamaGIS database for the 2011-2016 period. New media are represented in shades of blue.

area with a given radius. In this case, substantial extra costs should be taken into consideration.

The various sources of DamaGIS damage data were analysed (Fig. 1) to highlight the prominence of new media, accounting for three-quarters of the data collected (78\%). New media can be defined as the sources of information shared using digital technology such as blogs, social media, online media and websites. Using these new media makes it possible to obtain information at a fine spatial scale where traditional media are not always present.

Among the new media, social media holds a prominent place. It can be defined as "a group of Internet-based applications that build on the ideological and technological foundations of Web 2.0, and that allow the creation and exchange of user-generated content" (Kaplan and Haenlein, 2010). The rise of social media enables direct access to damage data from the people who are present during or after a flood event (Dashti et al., 2014; Fig. 2). Sources of information are therefore multiplied. This is a way to counterweigh the overrepresentation of large or more impacted cities during and after floods (Douvinet and Vinet, 2012).

Indeed, the use of social media in addition to traditional media will contribute to give more information about territories which get less traditional media coverage but have as much damage as territories with a strong media coverage. For instance, after the flood of the 3 October 2015 many municipalities have been affected by floods but traditional media have only focused their attention on two of them because of the fatalities.

Information on flood damage is collected in new media by entering flood-related keywords in search engines. Then the outcomes are sorted from the most recent to the oldest to be later assessed. When information is considered relevant with a precise location, it is added to the database. To obtain precise information on damage location, an extensive photographic recognition task was completed for non-localized 


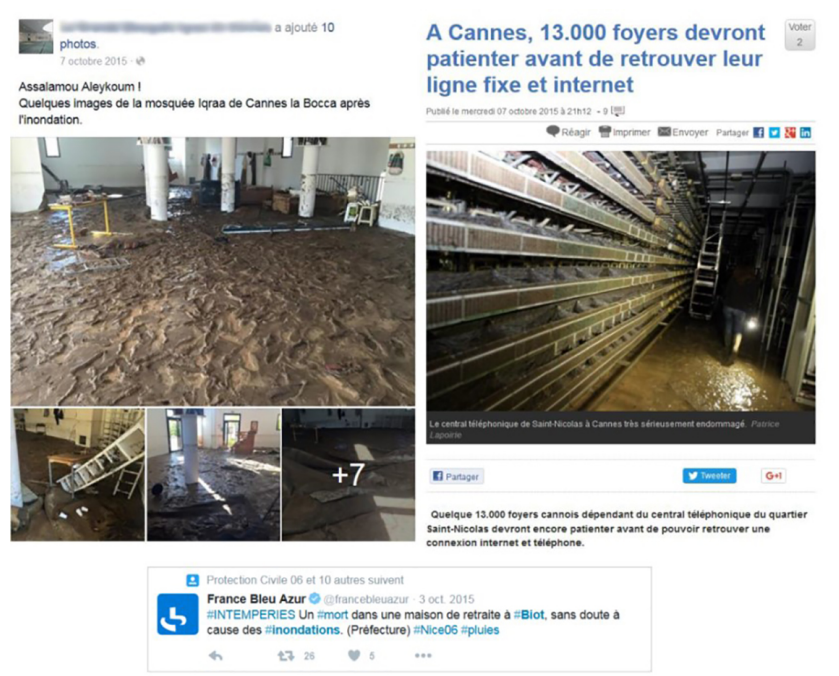

Figure 2. Examples of flood-related damage information publicly available in new media (from left to right and below: screenshot of the Facebook page of a mosque in Cannes, screenshot from the Nice-Matin newspaper website, and a screenshot of a tweet from the France Bleu Azur radio).

damage. This means deducing the location of a damaged element from a picture, using easily recognizable objects such as road signs, store fronts, vegetation, etc.

\subsection{Structure of the database}

From the different sources presented in the previous section, we extract what we call "damage data". It consists of information on damaged elements, with a time-stamp and a location. Each damaged element corresponds to a single object organized within the DamaGIS database, implemented as a geodatabase in the ArcGIS software to have a vectorial format for data tables in the form of feature classes. DamaGIS is based on a system with two feature classes interconnected by keys. The conceptual data model which organizes this system is presented in Fig. 3. Each DAMAGE entry is related to a row within the DAMAGE feature class and is connected to a single EVENT feature. However, one EVENT feature might refer to several DAMAGE entries. For both feature classes, the Lambert-93 reference system has been used because it is the reference system for national geographic data in France (Decree no 2006-272 of 3 March 2006). However, the use of Lambert-93 is specific to the French territory and not suitable for other countries. However, using a more generic coordinate system would cause a loss of precision in the damage location. Then, if needed, the coordinate system can be easily transformed using a geographic information system (GIS) software from Lambert-93 to a more generic coordinate system such as WGS84.

The first feature class is called "EVENT". It is a shape field containing polygon geometries for geographic features.

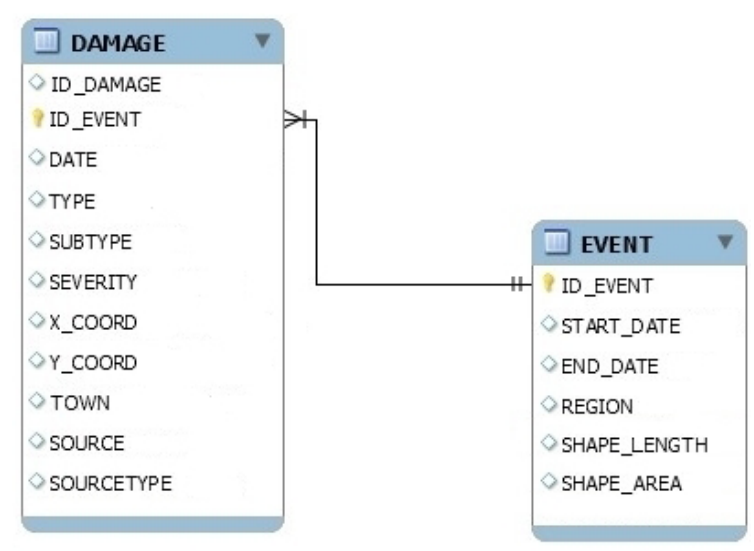

Figure 3. Data structure diagram organizing the connections between the DAMAGE and EVENT feature classes.

The EVENT feature class identifies flood events that have caused damage. We define a flood event as "the overflowing of one or several rivers due to a similar meteorological phenomenon that causes the flooding of lands that are normally dry". Since 2011, 23 flood events have been recorded in the south of France and included in the database. Each flood event corresponds to a polygon feature. It is related to a single row within the EVENT feature class and has a unique identifier. The polygon features correspond to French administrative entities known as departments (NUTS3 European level) where flood events have caused damage. The EVENT feature class contains six fields in addition to the shape field.

- ID_EVENT: unique identifier of the flood event,

- START_DATE: starting date of the flood event,

- END_DATE: ending date of the flood event,

- REGION: name of the area impacted by the event,

- Shape_Length: the length of the shapefile feature,

- Shape_Area: the area of the shapefile feature.

Both Shape_Length and Shape_Area attribute fields are automatically added during the creation of the polygon feature classes such as EVENT. Those fields can not be deleted and represent the length and area of the shapefile features,

More detailed information about flood events could have been included in the database such as magnitude or amount of cumulated rainfall during an event. However, this type of information has been kept separate. Instead, precise location and date of damage are provided. This enables the potential users to cross DamaGIS with any other data sources such as the research "FloodHymex database" (http://mistrals.sedoo. fr/HyMeX/?project_name=HyMeX) (Llasat et al., 2013).

The second and main feature class of the structure is the DAMAGE one, which catalogues flood-related damage. It 
is a shape field containing point geometries for geographic features. Each damage entry in the feature class is associated with a unique identifier and connected to a single flood event. Since 2011, 729 damage entries have been included in the DamaGIS geodatabase in the south of France. The DAMAGE feature class contains 11 fields besides the shape field.

- ID_DAMAGE: unique identifier of the damage entry,

- ID_EVENT: unique identifier of the flood event,

- DATE: date of the occurrence of the damage entry (“day/month/year" format),

- TYPE: type of damage (Table 1)

- SUBTYPE: subtype of damage (Table 1)

- SEVERITY: severity of damage (see Sect. 2.3.),

- X_COORD: x coordinates in Lambert-93 of the damaged element,

- Y_COORD: y coordinates in Lambert-93 of the damaged element,

- TOWN: municipality where the damaged element is located,

- SOURCE: source of information on the damage entry,

- SOURCETYPE: type of source.

\subsection{Type of damaged element}

To facilitate the exploitation of this geodatabase, potential damaged elements are sorted into 15 types presented in Table 1. Each type of damaged element might also contain several subtypes. These different categories of damaged elements were obtained from an adaptation of the classes used by the BD Topo ${ }^{\circledR}$ generated by the French National Geographic Institute (IGN). This vector database offers a description of geographic objects relating to land use and infrastructure. For now, there are no subtypes for water and electric networks because the data we had access to did not have this level of detail. But these subtypes could be added and shared in the future if needed by a specific user of the database.

DamaGIS does not take fatalities into account. The choice was made so as to focus only on material damage. However, information on flood-related fatalities is included in another database called the Vict-In database, which has gathered the circumstances of death and the profiles of the flood victims in the French Mediterranean departments since 1988 (Boissier, 2013; Vinet et al., 2016). Both Vict-In and DamaGIS share the same EVENT feature class.

Given the very wide range of damage types within the database, an appropriate rating system had to be found to assess their severity on a comparable basis. The severity assessed for each damage entry can be found within the DAMAGE feature class with the "SEVERITY" field. In the following section, this rating system is presented and explained.

\section{The rating system for flood-related damage}

Damage assessment methodologies usually focus on assessing potential future flood damage. But in this paper we chose to focus on the assessment of post-flood damage for feedback purposes. Damage assessment almost always includes the assessment of direct and tangible damage because it is easier to identify and quantify. However, although there are numerous methods to assess the severity of this type of damage, they vary greatly in their content. Indeed, there is substantial heterogeneity among damage assessment methodologies depending on their purpose (Bouwer et al., 2007)

Damage severity may be expressed in raw monetary value, percent loss estimates, an index value on a scale, a numerical standardized value on a scale from 0 to 1 or a range of indicators (Blong, 2003b). In the literature, damage is often assessed with the replacement cost or the value of the impaired element (Jongman et al., 2012; Merz et al., 2010; Olesen et al., 2017). One major disadvantage of this kind of approach is that it weakens the possible comparison between two flood events (Blong, 2003a). Indeed, depending on where and when a flood event occurs, there might be a considerable variation in costs.

The objective of the damage assessment method presented in this paper was to easily gather and compare different types of damage regardless of the nature of the damaged element. The aim is not to obtain an economic evaluation but a functional assessment of damage. This approach also makes it possible to obtain objective information on damage severity. Different studies suggest that the analysis of damage severity over time and space is made difficult by the absence or low quality of available databases on flood damage and the lack of consensus upon flood data collection (Sene, 2012). With the DamaGIS database, this type of approach is made possible by using a simple rating scale operating on a range of damage indicators. This scale enables comparison over time and space as well as for a single flood severity category; the functional consequences of a flood on an element will stay the same.

We use an ordinal scale, which means that the greater the damage is, the higher the value is on the scale. However, neither the value of the scale level nor the difference between two scale levels is meaningful separately (Velleman and Wilkinson, 1993). This scale is made up of four levels, shaped like a decision tree, ranging from level one to level four (Fig. 4). To illustrate this scale, we might use the example of a road whose primary function is to provide land access. 
Table 1. Types and subtypes of damaged elements within the DAMAGE feature class.

\begin{tabular}{|c|c|c|c|c|c|}
\hline Type & Subtype(s) & & & & \\
\hline Agriculture & Animal husbandry & Cultivation & & & \\
\hline Crisis management & Firehouse & $\begin{array}{l}\text { Centre of crisis } \\
\text { management }\end{array}$ & Police station & & \\
\hline \multirow{2}{*}{$\begin{array}{l}\text { Economic activity } \\
\text { Electric network }\end{array}$} & Store & Business & Association & & \\
\hline & Small road & One-lane road & Two-lane road & Highway & Boulevard \\
\hline Road network & Avenue & Street & Passage & Bridge & $\begin{array}{l}\text { Motorway } \\
\text { interchange }\end{array}$ \\
\hline School & Pre-school & Elementary & Junior-high & High-school & University \\
\hline Seasonal accommodation & Camping & Hotel & Lodging & & \\
\hline Government service, administration & Town hall & & & & \\
\hline $\begin{array}{l}\text { Transport building } \\
\text { Water network }\end{array}$ & Train station & Airport & Bus station & & \\
\hline Health & Nursing home & Hospital & & & \\
\hline Housing & Individual & Collective & & & \\
\hline \multicolumn{6}{|l|}{ Rail Network } \\
\hline Parking & Underground & Outdoor & & & \\
\hline Public place of recreation & Sport facility & Park & Place of worship & Museum & \\
\hline
\end{tabular}

- The first level of damage severity corresponds to the flooding of an element without the loss of its function. For example, a road is flooded but cars can still drive on it.

- The second level means that the flooding caused the loss of the element's function for fewer than 3 days. For example, a road is flooded and cars cannot drive on it for a day.

- The third level of severity indicates an interruption time of the flooded element function longer than 3 days. For example, a road is flooded and cars cannot drive on it for a week.

- Finally, the fourth severity level is based on the destruction of the element by the flood. For example, a road is destroyed by a flood.

This approach is midway between the assessment of direct and indirect damage given that we chose to express damage severity as a loss of function. Direct damage is usually measured in terms of monetary loss and loss of function is commonly associated with indirect damage. However, we consider that the loss of function is a direct effect of flooding on an element because it affects the purpose for which it exists.

\section{Analysis}

Since 2011, the DamaGIS database has been completed with 729 damage entries amongst 23 flash flood events in the south of France (Fig. 5). It might seem difficult to draw

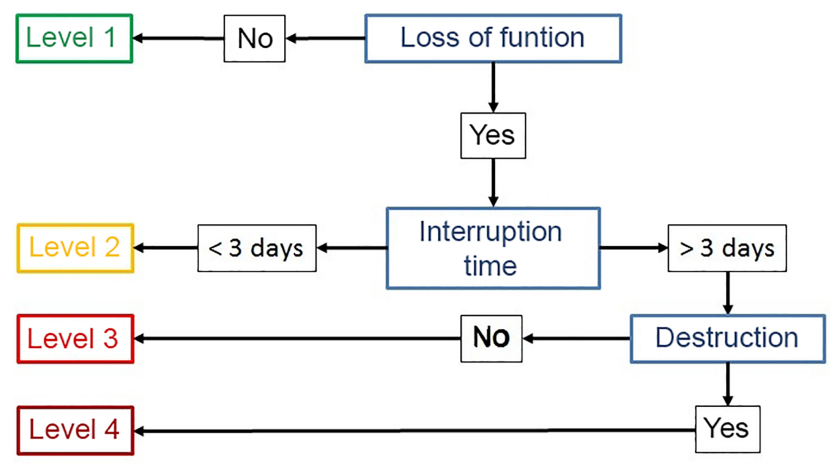

Figure 4. Illustration of the measurement scale used to assess damage severity.

conclusions for such a reduced period of time, but the next section will attempt to provide an overview of the entire database content entered to date.

According to the database, two main categories of damaged elements seem to be more affected by floods: $23.6 \%$ of the damage entries involves an economic activity, while $23.5 \%$ affects the road network (Fig. 6). The overrepresentation of these two types of elements can be explained by different factors.

In the case of economic activities, information is easily accessible through traditional media as well as new media. It is not unusual that these entities own a web page to advertise. Similarly, a strong presence on social media can also be highlighted. In the case of a flood, numerous economic 

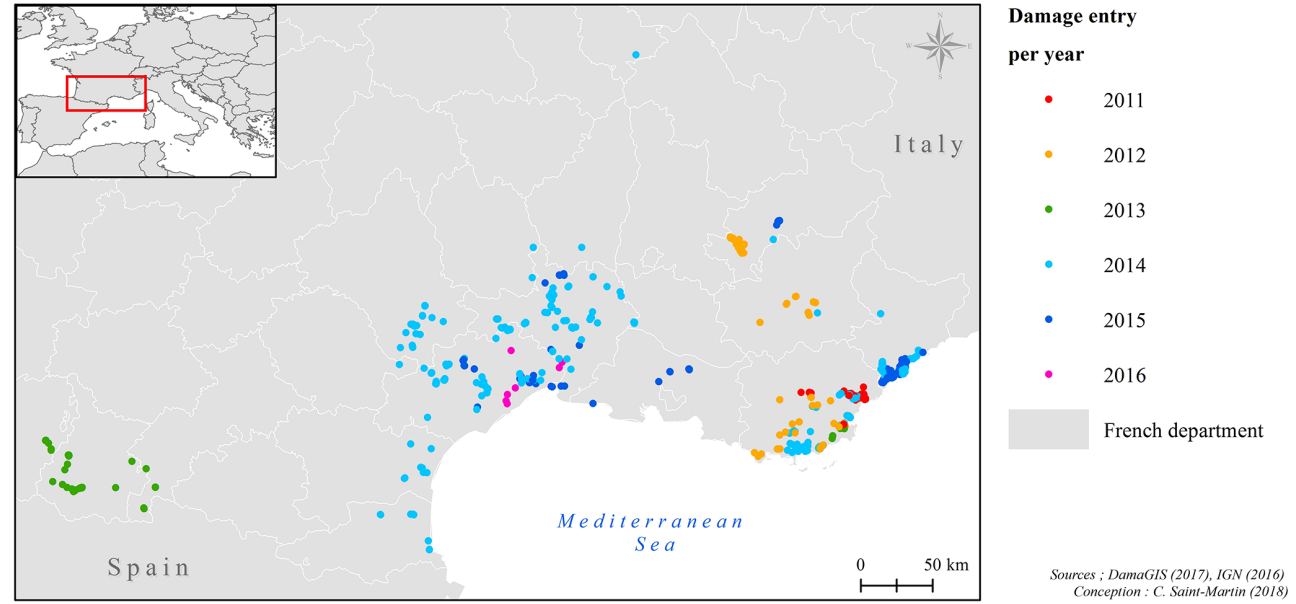

Figure 5. Spatial distribution of flood-related damage within the DamaGIS database.

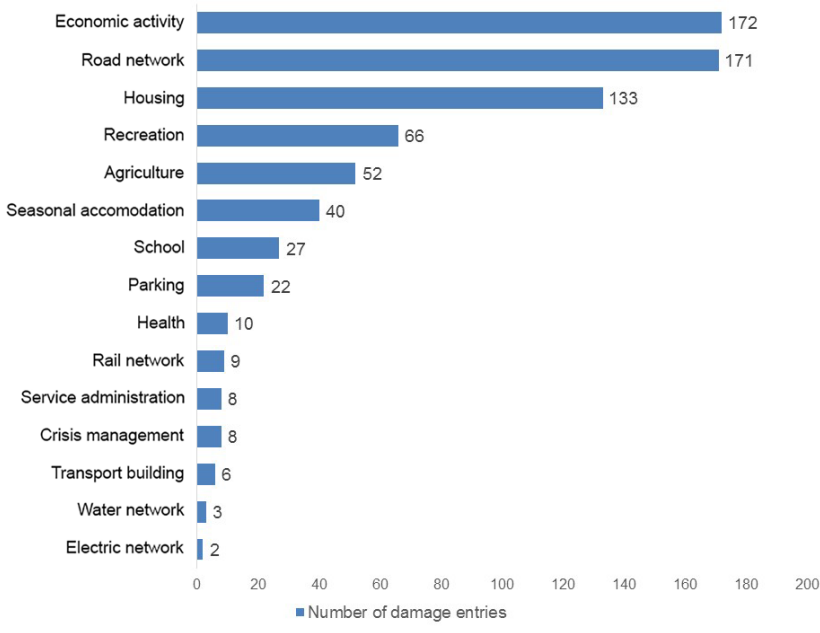

Figure 6. Number of flood-related damage events by type of element affected since 2011 in the south of France.

activities often contact their clients through either one of these two means to update them on the situation because floods may affect their functioning. In terms of indirect input to the database, economic activities are easily recognizable on unidentified pictures because of distinctive signs such as shop signs.

Two main reasons for road network damage as recorded in the database can be cited. First of all, the road network is extensive and dense, and highly exposed to flooding (Naulin et al., 2013). This can be illustrated by the circumstances involved in deaths related to floods. For instance, since 1982, $30 \%$ of flood-related fatalities in the south of France were caused by a vehicle driven on a flooded road (Boissier, 2013). Secondly, information on flooded roads is easily accessible by means of navigation software available to the public. Moreover, local authorities increasingly tend to monitor and

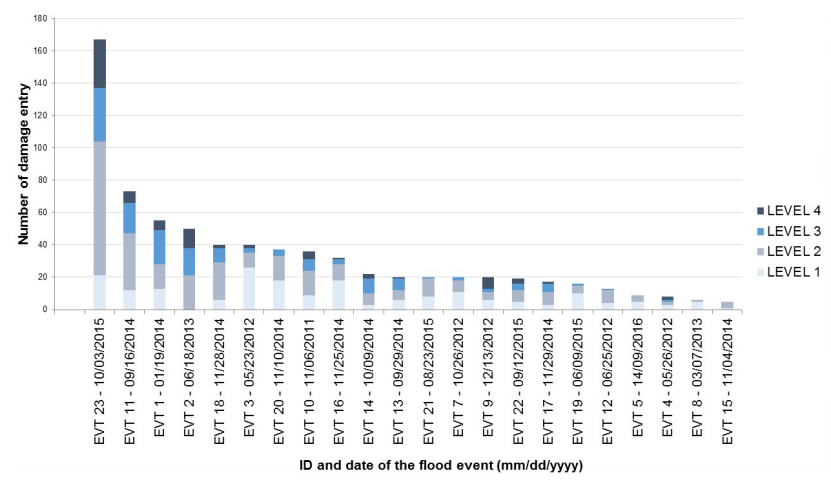

Figure 7. Severity and number of damage entries per flood event.

share information on social media and by radio concerning the condition of the road network to keep the public informed (Bunce et al., 2012; Cheong and Cheong, 2011; Latonero and Shklovski, 2011).

Regarding the severity of damage, flood events are not equally distributed among the four levels. For instance, the second level of severity is the most frequent within the database (Fig. 7). This level comprises 302 damage entries while the first level has 194 and the third and fourth levels 151 and 82 entries, respectively. These differences may be caused by the use of a short-term series of damage data. Due to the limited size of the database, the damage data may not be fully representative. For this reason, the results of the database analysis need to be interpreted cautiously.

\section{The 3 October 2015 flood event}

The average number of damage entries per flood event within the database is about 32. Four of these flood events seem to stand out with more than 50 damage entries. These events took place in 2013, 2014 and 2015. The most damaging flood 


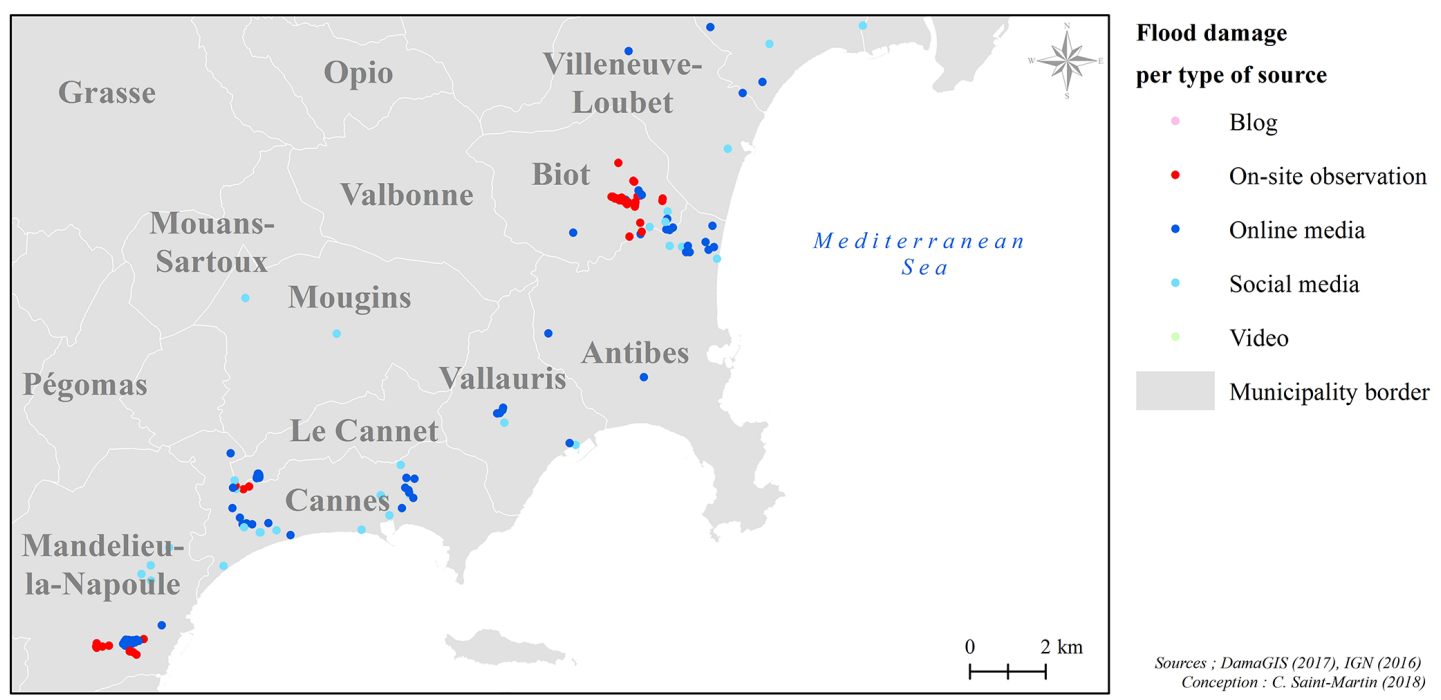

Figure 8. Spatial distribution of damage from 3 October 2015 flood according to their sources.

event within the database occurred on 3 October 2015 in the Alpes-Maritimes region (Fig. 7).

There are as many entries associated with this event, as for the other three major floods within the database (Fig. 7). Therefore, it seems relevant to focus on this particular event. On 3 October 2015, a storm produced more than $175 \mathrm{~mm}$ of rainfall in $2 \mathrm{~h}$ and caused significant flash floods in a short period of time on small basins in the Alpes-Maritimes region (Javelle et al., 2015). This flood event caused 20 fatalities and more than EUR 650 million of damage (Direction Territoriale Méditerranée du Cerema, 2015).

Within the DamaGIS database, 167 damage entries refer to this specific event. They are distributed among 14 towns and villages in the Alpes-Maritimes region. The main data sources are social networks, online media and fieldwork. The fieldwork has made it possible to obtain localized information about three specific zones in the Mandelieu-la-Napoule, Biot and Cannes municipalities, while online and social media provided information on larger zones (Fig. 8).

Regarding the type of damage, the over-representation of damaged housing might be underlined in comparison with other flood events. Indeed, housing represents more than onethird of the damage entries within the DamaGIS database, even though it accounts for only one-tenth of the entire database. This discrepancy might be explained by the large number of damage entries obtained with fieldwork. Indeed, it is easier to obtain information about damage in residential areas on site. This example underlines why it is important to use multiple sources of data to improve the comprehensiveness and quality of data.

\section{Data availability}

The DamaGIS open-access database and its description are available at the following link: https://doi.org/10.5281/zenodo.1241089.

\section{Conclusions and outlook}

\section{Benefits of the database}

Amongst the main benefits of the DamaGIS database, the high resolution of the data available within the database can be highlighted. Indeed, the use of the building scale provides significantly detailed information. There is currently no other open access database offering this level of detail.

The simplicity of use and data entry of the database must also be underlined. For it to be continued, DamaGIS depends on a wide range of contributors that must be able to easily add information to the current database. To this end, this paper has presented a new scale to assess damage severity. This scale makes it possible to compare and contrast damage data regardless of the type of information, and across time and space. In that respect, the DamaGIS database can be easily used in other areas than the south of France. The implementation of this fine scale is in itself an innovative approach.

The DamaGIS database also uses multisource data including social media. This presents many advantages, notably its ability to obtain damage data rapidly after a flood without necessarily having to necessarily go on site.

Finally, one of the main advantages of the database is its format. As a geodatabase, DamaGIS can be used as a simple database to be accessed through GIS software. The vectorial format of the feature classes within the database allows one to easily visualize and represent the data these categories contain. 


\section{Limitations of the database}

Despite the advantages of the DamaGIS database presented in the previous section, certain questions and concerns should be addressed. First, this database only focuses on damage caused by flood events in the south of France since 2011. Consequently, the available data time series are relatively short and do not yet allow relevant statistical analysis.

Secondly, the use of new media may raise concerns about the discrepancies among the sources of information. Indeed, according to a recent study, French people aged 50 and above are unwilling to use social media and do not know how to properly use the Internet (Douvinet et al., 2017). They make up $38 \%$ of the French population (INSEE, 2017). It should also be underlined that there is one major drawback about the use of online or social media; some data won't be available online after several years.

Finally, it must be underscored that the database is not comprehensive. Some information might be eluded during the search process. Moreover, certain required information about damage data might not be available with the data sources used in this DamaGIS. This is why the need for collaborative work from a variety of contributors as well as a multisource approach are encouraged in the future.

\section{Perspectives}

From the various benefits and limits addressed in the previous section, many prospects can be highlighted for the DamaGIS database.

As discussed above, even though the database has only focused on the south of France for now, it can easily be applied to different areas given its high adaptability and simplicity of use. Due to the time-consuming process for damage collection, an online platform could be considered in the future to encourage collaborative work as well as the creation of multistakeholder working groups. We also consider that such a participatory work should be moderated by a dedicated institution such as local or national authorities.

The current content of the DamaGIS database is framed at a fine spatial scale: damage data are provided at the building scale. This means that damage data available at a larger scale are not included within the database. However, to prevent the database contributors from excluding valuable but less precise data, a quality index could be provided to assess the geographic accuracy of the data. For instance, a damage data available at the building scale would have a high index, while damage data at the neighbourhood scale would have a low one. In the same vein, an index to assess the temporal accuracy of the data might be considered.

At this time, however, one of the main and most immediate prospects for the DamaGIS database would be its use for modelling purposes. For instance, DamaGIS has already been used in this regard in Saint-Martin et al. (2016). Currently flood damage data are needed to calibrate and validate flood damage models at a fine scale. In this respect, this paper presents a new approach to compile and assess flood-related damage data from multiple sources in a participatory type of functioning within the DamaGIS database.

Competing interests. The authors declare that they have no conflict of interest.

Acknowledgements. The authors would like to thank the SCHAPI (French central office for hydrometeorology and assistance to flood forecasting) as well as the Palladio Foundation for their financial support to this work. The authors would also like to thank the reviewers for their willingness to thoroughly evaluate and improve this work.

Edited by: Giulio G.R. Iovine

Reviewed by: Olivier Payrastre and four anonymous referees

\section{References}

Alfieri, L., Feyen, L., Dottori, F., and Bianchi, A.: Ensemble flood risk assessment in Europe under high end climate scenarios, Global Environ. Change, 35, 199-212, https://doi.org/10.1016/j.gloenvcha.2015.09.004, 2015.

Blong, R.: A review of damage intensity scales, Nat. Hazards, 29, 57-76, 2003a.

Blong, R.: A new damage index, Nat. Hazards, 30, 1-23, 2003 b.

Boissier, L.: La mortalité liée aux crues torrentielles dans le Sud de la France: une approche de la vulnérabilité humaine face à l'inondation, Université Paul Valéry-Montpellier III, 2013.

Bourguignon, D.: Événements et territoires-le coût des inondations en France: analyses spatio-temporelles des dommages assurés, Université Paul Valéry-Montpellier III, 2014.

Bouwer, L. M., Crompton, R. P., Faust, E., Höppe, P., and Pielke Jr., R. A.: Confronting disaster losses, Science, New York then Washington, 318, 753, 2007.

Bubeck, P., de Moel, H., Bouwer, L. M., and Aerts, J. C. J. H.: How reliable are projections of future flood damage?, Nat. Hazards Earth Syst. Sci., 11, 3293-3306, https://doi.org/10.5194/nhess11-3293-2011, 2011.

Bunce, S., Partridge, H., and Davis, K.: Exploring information experience using social media during the 2011 Queensland Floods: a pilot study, The Aust. Library J., 61, 34-45, https://doi.org/10.1080/00049670.2012.10722300, 2012.

Calianno, M., Ruin, I., and Gourley, J. J.: Supplementing flash flood reports with impact classifications, J. Hydrol., 477, 1-16, https://doi.org/10.1016/j.jhydrol.2012.09.036, 2013.

CCR: Floods of may-June 2016 in France: Modeling the risks and damages, available at: https: //www.ccr.fr/documents/23509/29230/Inondations+de+ Seine+et+Loire+mai+2016_ANGLAIS_DEF+OK.pdf/ ad34f06c-ea26-4318-a602-04c9a82302f0 (last access: 8 January 2018), 2016.

CCR (Caisse Centrale de Réassurance): available at: https://www. ccr.fr/, last access: 9 June, 2017. 
Cheong, F. and Cheong, C.: Social Media Data Mining: A Social Network Analysis Of Tweets During The 2010-2011 Australian Floods, PACIS, 11, 46-46, 2011.

Dashti, S., Palen, L., Heris, M. P., Anderson, K. M., Anderson, T. J., and Anderson, S.: Supporting disaster reconnaissance with social media data: A design-oriented case study of the 2013 Colorado floods, ISCRAM, 2014,

Dilley, M.: Natural disaster hotspots: a global risk analysis, World Bank Publications, 2005.

Direction Territoriale Méditerranée du Cerema: Retour d'expérience sur les inondations des Alpes-Maritimes des 3 et 4 octobre 2015, Contribution partielle au GT3, Contribution du GT4, Rapport d'étape au 23/11/15, 37, 2015.

Douvinet, J. and Vinet, F.: La carte des arrêtés" CatNat" pour les inondations: limites et améliorations possibles, Mappemonde, 107, 17-30, 2012.

Douvinet, J., Gisclard, B., Kouadio, J. S., Saint-Martin, C., and Martin, G.: Une place pour les technologies smartphones et les Réseaux Sociaux Numériques (RSN) dans les dispositifs institutionnels de l'alerte aux inondations en France?, Cybergeo: European Journal of Geography [En ligne], Espace, Société, Territoire, document 801, available at: http://journals.openedition.org/ cybergeo/27875, last access: 28 May 2018.

Downton, M. W., Miller, J. Z. B., and Pielke Jr., R. A.: Reanalysis of US National Weather Service flood loss database, Nat. Hazards Rev., Vol. 6, 13-22, 2005.

Elmer, F.: Improving flood damage modelling: damage assessment, model development and application, Potsdam : Deutsches GeoForschungsZentrum GFZ xxii, 160, CII S. pp., 2012.

Gerl, T., Kreibich, H., Franco, G., Marechal, D., and Schröter, K.: A Review of Flood Loss Models as Basis for Harmonization and Benchmarking, PLoS ONE, 11, e0159791, https://doi.org/10.1371/journal.pone.0159791, 2016.

Gourley, J. J., Hong, Y., Flamig, Z. L., Arthur, A., Clark, R., Calianno, M., Ruin, I., Ortel, T., Wieczorek, M. E., and Kirstetter, P.-E.: A unified flash flood database across the United States, B. Am. Meteorol. Soc., 94, 799-805, 2013.

Guha-Sapir, D. and Below, R.: The quality and accuracy of disaster data: A comparative analyse of 3 global data sets, Disaster Management facility, World Bank, Working paper ID, 2002.

Guha-Sapir, D., Below, R., and Hoyois, P.: EM-DAT: International disaster database, Catholic University of Louvain: Brussels, Belgium, 2015.

Guzzetti, F., Cardinali, M., and Reichenbach, P.: The AVI project: a bibliographical and archive inventory of landslides and floods in Italy, Environ. Manage., 18, 623-633, 1994.

Hoyois, P. and Guha-Sapir, D.: Three decades of floods in Europe: a preliminary analysis of EMDAT data, WHO collaborating centre for research on the epidemiology of disasters (CRED), Catholique University of Louvain, 2003.

INSEE, Population par sexe et groupe d'âges en 2018, available at: http://www.insee.fr/, last access date: 17 February 2018.

Javelle, P., Catherine, F., Clotilde, S.-M., Stephane, E., Mathieu, T., Philippe, C., Jean, O., Patrice, M., and Patrick, A.: Retour sur les inondations du 03 octobre 2015 dans les Alpes-Maritimes vues par la méthode AIGA - Note provisoire - Version 1, 19 October 2015, p. 26, 2015.

Jongman, B., Kreibich, H., Apel, H., Barredo, J. I., Bates, P. D., Feyen, L., Gericke, A., Neal, J., Aerts, J. C. J. H., and Ward, P.
J.: Comparative flood damage model assessment: towards a European approach, Nat. Hazards Earth Syst. Sci., 12, 3733-3752, https://doi.org/10.5194/nhess-12-3733-2012, 2012.

Kaplan, A. M. and Haenlein, M.: Users of the world, unite! The challenges and opportunities of Social Media, Business Hor., 53, 59-68, https://doi.org/10.1016/j.bushor.2009.09.003, 2010.

Kreibich, H., Thieken, A., Haubrock, S.-N., and Schröter, K.: HOWAS21, the German Flood Damage Database, in: Flood Damage Survey and Assessment, John Wiley \& Sons, Inc., 65$75,2017$.

Kron, W., Steuer, M., Löw, P., and Wirtz, A.: How to deal properly with a natural catastrophe database - analysis of flood losses, Nat. Hazards Earth Syst. Sci., 12, 535-550, https://doi.org/10.5194/nhess-12-535-2012, 2012.

Latonero, M. and Shklovski, I.: Emergency management, Twitter, and social media evangelism, 2011.

Llasat, M. C., Llasat-Botija, M., Petrucci, O., Pasqua, A. A., Rosselló, J., Vinet, F., and Boissier, L.: Towards a database on societal impact of Mediterranean floods within the framework of the HYMEX project, Nat. Hazards Earth Syst. Sci., 13, 13371350, https://doi.org/10.5194/nhess-13-1337-2013, 2013.

Merz, B., Kreibich, H., Schwarze, R., and Thieken, A.: Review article "Assessment of economic flood damage", Nat. Hazards Earth Syst. Sci., 10, 1697-1724, https://doi.org/10.5194/nhess10-1697-2010, 2010.

Mileti, D.: Disasters by design: A reassessment of natural hazards in the United States, Joseph Henry Press, 1999.

Molinari, D., Legnani, L., di Lecco, P. T., and Di Architettura, D.: La procedura Flood-IMPAT per la valutazione e mappatura del rischio alluvionale, 2013.

Molinari, D., Menoni, S., and Ballio, F.: Flood Damage Survey and Assessment: New Insights from Research and Practice, John Wiley \& Sons, Inc., Hoboken, NJ, USA, 2017.

Munich RE: Year of the floods, TOPICS GEO, p. 80, 2017.

Napolitano, E., Marchesini, I., Salvati, P., Donnini, M., Bianchi, C., and Guzzetti, F.: LAND-deFeND - An innovative database structure for landslides and floods and their consequences, J. Environ. Manage., 207, 203-218, 2018.

National Climatic Data Center: Storm Events Database, available at: https://www.ncdc.noaa.gov/stormevents/ (last access: 1 December 2017), 2015.

Naulin, J.-P., Payrastre, O., and Gaume, E.: Spatially distributed flood forecasting in flash flood prone areas: Application to road network supervision in Southern France, J. Hydrol., 486, 88-99, 2013.

NRC: The impacts of natural disasters: A framework for loss estimation, National Academies Press, 1999.

Olesen, L., Löwe, R., and Arnbjerg-Nielsen, K.: Flood damage assessment - Literature review and recommended procedure, Melbourne, Australia: Cooperative Research Centre for Water Sensitive Cities, 2017.

Ortega, K. L., Smith, T. M., Manross, K. L., Kolodziej, A. G., Scharfenberg, K. A., Witt, A., and Gourley, J. J.: The severe hazards analysis and verification experiment, B. Am. Meteorol. Soc., 90, 1519-1530, 2009.

Pachauri, R. K., Allen, M. R., Barros, V. R., Broome, J., Cramer, W., Christ, R., Church, J. A., Clarke, L., Dahe, Q., and Dasgupta, P.: Climate change 2014: synthesis report. Contribution of Working 
Groups I, II and III to the fifth assessment report of the Intergovernmental Panel on Climate Change, IPCC, 2014.

Parker, D. J.: Floods, edited by: Parker, D., Vol. 1, London: Routledge, 2000.

Parker, D., Green, C., and Thompson, P.: Urban Flood protection Benefits, a project appraisal guide "The Red Book", Gower Publishing Company, Brookfield, USA, 1987.

Pigeon, P.: Réflexions sur les notions et les méthodes en géographie des risques dits naturels, Ann. Géogr., 111, 452-470, 2002.

Ramos, M. H., Perrin, C., Andréassian, V., Olivier Delaigue, and Viatgé, J.: Assessment report on the 2016 flood event on the Seine and Loire basins (France), Final report, European Flood Awareness System (EFAS) dissemination centre, Rijkswaterstaat (NL), Vigicrues network/SCHAPI (France), Irstea (France), p. 43, 2017.

Saint-Martin, C., Fouchier, C., Javelle, P., Douvinet, J., and Vinet, F.: Assessing the exposure to floods to estimate the risk of floodrelated damage in French Mediterranean basins, 3rd European Conference on Flood Risk Management (FLOODrisk 2016), 04013, 2016.

Saint-Martin, C.: DamaGIS [Data set], Zenodo, available at: http: //doi.org/10.5281/zenodo.1241089, last access: 6 March 2018.
Sene, K.: Flash floods: forecasting and warning, Springer Science \& Business Media, 2012.

Smith, K. and Ward, R.: Floods: physical processes and human impacts, John Wiley and Sons Ltd, 1998.

Tschoegl, L., Below, R., and Guha-Sapir, D.: An analytical review of selected data sets on natural disasters and impacts, Centre for Research on the Epidemiology of Disasters Louvain, 2006.

UNISDR: Proceedings of the third UN World Conference on Disaster Reduction, UN World Conference on Disaster Risk Reduction, 14-18 March 2015, Sendai, Japan, p. 169, 2015.

van Oldenborgh, G. J., Philip, S., Aalbers, E., Vautard, R., Otto, F., Haustein, K., Habets, F., Singh, R., and Cullen, H.: Rapid attribution of the May/June 2016 flood-inducing precipitation in France and Germany to climate change, Hydrol. Earth Syst. Sci. Discuss., https://doi.org/10.5194/hess-2016-308, 2016.

Velleman, P. F. and Wilkinson, L.: Nominal, ordinal, interval, and ratio typologies are misleading, The Am. Stat., 47, 65-72, 1993.

Vinet, F., Boissier, L., and Saint-Martin, C.: Flashflood-related mortality in southern France: first results from a new database, E3S Web Conf., 7, 06001, 2016.

Wallemacq, P., Guha-Sapir, D., McClean, D., Cred, and Unisdr: The Human Cost of Weather Related Disasters - 1995 - 2015, 2015. 